\title{
BMJ Open Evaluating the implications of Brexit for research collaboration and policy: a network analysis and simulation study
}

\author{
George Garas, ${ }^{\oplus 1}$ Isabella Cingolani, ${ }^{2}$ Vanash M Patel, ${ }^{1}$ Pietro Panzarasa, ${ }^{\oplus}$ \\ Ara Darzi, ${ }^{1}$ Thanos Athanasiou ${ }^{1}$
}

To cite: Garas G, Cingolani I, Patel VM, et al. Evaluating the implications of Brexit for research collaboration and policy: a network analysis and simulation study. BMJ Open 2019;9:e025025. doi:10.1136/ bmjopen-2018-025025

- Prepublication history and additional material for this paper are available online. To view these files, please visit the journal online (http://dx.doi org/10.1136/bmjopen-2018025025).

Received 26 June 2018 Revised 20 April 2019 Accepted 08 July 2019

Check for updates

(c) Author(s) (or their employer(s)) 2019. Re-use permitted under CC BY-NC. No commercial re-use. See rights and permissions. Published by BMJ.

${ }^{1}$ Department of Surgery and Cancer, Imperial College London, St. Mary's Hospital, London, UK ${ }^{2}$ Big Data and Analytical Unit, Imperial College London, St. Mary's Hospital, London, UK

${ }^{3}$ School of Business and Management, Queen Mary University of London, London, UK

Correspondence to

Dr George Garas;

g.garas@imperial.ac.uk

\section{ABSTRACT}

Objective To evaluate the role of the European Union (EU) as a research collaborator in the UK's success as a global leader in healthcare research and innovation and quantify the impact that Brexit may have.

Design Network and regression analysis of scientific collaboration, followed by simulation models based on alternative scenarios.

Setting International real-world collaboration network among all countries involved in robotic surgical research and innovation.

Participants 772 organisations from industry and academia nested within 56 countries and connected through 2397 collaboration links.

Main outcome measures Research impact measured through citations and innovation value measured through the innovation index.

Results Globally, the UK ranks third in robotic surgical innovation, and the EU constitutes its prime collaborator. Brokerage opportunities and collaborators' geographical diversity are associated with a country's research impact ( $c=211.320$ and 244.527, respectively; $p<0.01$ ) and innovation ( $c=18.819$ and 30.850 , respectively; $p<0 \cdot 01$ ). Replacing EU collaborators with US ones is the only strategy that could benefit the UK, but on the condition that US collaborators are chosen among the top-performing ones, which is likely to be very difficult and costly, at least in the short term.

Conclusions This study suggests what has long been argued, namely that the UK-EU research partnership has been mutually beneficial and that its continuation represents the best possible outcome for both negotiating parties. However, the uncertainties raised by Brexit necessitate looking beyond the EU for potential research partners. In the short term, the UK's best strategy might be to try and maintain its academic links with the EU. In the longer term, strategic relationships with research powerhouses, including the USA, China and India, are likely to be crucial for the UK to remain a global innovation leader.

\section{INTRODUCTION}

On 23 June 2016, the UK voted to leave the European Union (EU) through the Brexit referendum. Since then there has been a dramatic rise in the number of publications on Brexit and its potential impact on the

\section{Strengths and limitations of this study}

- This study is the first of its kind in surgical research, using network analysis and simulation modelling, to examine the impact of Brexit on a key area in which the UK is set to be a global leader.

- It comes at a very critical time point when the level of participation of the UK in future European Union (EU) programmes on science and innovation is still to be negotiated.

- The UK's real-world international collaboration network was constructed and analysed making this study of practical value to the UK government, its negotiators and policy-makers when it comes to setting priorities, making decisions and devising international strategies following Brexit.

- Limitations are mainly concerned with the focus of the analysis on a very specific field, which does not make it straightforward to generalise results to other domains.

- The simulation models employed are conservative, as the potential loss of EU funding and/or human capital as a result of Brexit was not accounted for.

UK's performance across various sectors. ${ }^{1-3}$ A number of quantitative studies have been produced on the impact that Brexit might have on the UK's economy, trade and industries. ${ }^{4-8}$ However, the majority of these studies in the scientific and healthcare literature have resulted in editorials and letters expressing individuals' as well as scientific and industrial bodies' concerns. ${ }^{19-13}$ With only few exceptions (eg, one recent work in the field of scientometrics), ${ }^{14}$ even the handful of studies on the impact of Brexit on healthcare, research and innovation are limited to narrative descriptions of possible scenarios, and thus fail to provide any measurement of the reported expected impact. ${ }^{21516}$ To preserve the UK's global leading position in healthcare innovation, the measurement of impact is needed that can inspire the development of a coherent set of policies for each scenario. 
As robotics features at the top of the UK government's Eight Great Technologies initiative, ${ }^{17}$ this study aims to assess the contribution of the EU to the UK's success as a global leader in robotic surgery. Simulation-based studies have been carried out to evaluate how the UK's prominent position could be preserved (or even improved) in the event that UK-EU research collaborations should deteriorate significantly. These studies leverage network analysis to provide visual maps and a quantitative assessment of collaborative patterns and their association with innovation. ${ }^{18}$ The findings may assist policy-makers in directing the UK's international strategy post-Brexit with a view to ensuring downsides are mitigated and opportunities beyond the EU seized.

\section{METHODS}

\section{The dataset}

All articles on robotic surgery were extracted from the Web of Science platform (Clarivate Analytics, Philadelphia, Pennsylvania, USA). The search was performed on 17 January 2017, and produced 3866 peer-reviewed articles published between July 1988 and January 2017 (see online supplementary S.1, figure S1 and table S1 for details), which were then used to construct the international collaboration network. Any article that did not represent original research studies on robotic surgery (eg, review article or conference article) was excluded.

\section{The International collaboration network}

The international collaboration network was constructed and analysed using MATLAB (The MathWorks, Natick, Massachusetts, USA). To this end, this study has adopted the widely established practice of using coauthorship of articles as a proxy for scientific collaboration. ${ }^{19-21}$ First, a network comprising 2397 collaboration links connecting 772 organisations across 56 countries and 7 geographical regions was constructed (online supplementary appendix). Links and nodes were then aggregated to produce a real-world collaboration network between countries. In this network, each node represents a country, and links between nodes represent collaborations between countries. This is a weighted network in which each link is associated with a value reflecting the intensity of the collaboration between the connected nodes (see online supplementary S.2 for details).

\section{Patient and public involvement}

The ideas and design of this study have been formed through long-standing discussions with members of the public (including patients), academics, policy-makers and the industry.

\section{Outcome measures}

Two outcome measures were calculated at the national level:

\section{Research impact (snc)}

This was measured as the sum of the research performance of all organisations residing in a given country. In turn, for each organisation, academic performance was measured by computing the sum of the normalised citations received by all articles published by the organisation across the years. To obtain normalised citations, the citation count for each publication in a given year was divided by the average number of citations obtained by all articles published in the same year (see online supplementary S.3.1 and S.4 for details).

\section{Innovation index (iii)}

This metric was specifically developed for the measurement of surgical innovation. It is based on surgical implementation stages and levels of evidence associated with articles, and was validated against real-world data from the clinical setting. We measured the innovation index of a given country as the sum of the innovation indices of all organisations residing in the country. In turn, for a given organisation, the innovation index was computed as a function of the innovative value of all articles published by authors affiliated with that organisation (see online supplementary S.3.1, figures S2-S3 and table S2 for details). ${ }^{18}$

\section{Network measures}

A number of measures were computed to capture the structural position that each country occupies in the global collaboration network (see online supplementary S.5.1-S.5 for details). ${ }^{1822} 23$

\section{Degree $\left(\mathrm{k}_{\mathrm{i}}\right)$}

This is defined as the number of a node's direct links to other nodes, that is, the number of countries a focal country collaborates with. A country i has a link with a country $\mathrm{j}$ if there is at least one organisation in $\mathrm{i}$ that collaborates with the at least one organisation residing in $\mathrm{j}$. Thus, a link between two countries $\mathrm{i}$ and $\mathrm{j}$ implies that there are at least two scientists, one affiliated with an organisation in country $i$ and the other in country $j$, that have coauthored at least one publication, thus generating a collaborative link between the corresponding countries (see online supplementary S.5.1 for details). ${ }^{19} 22$

\section{Effective size (es)}

This measure captures the extent to which a focal node is connected to non-redundant nodes, thus reflecting brokerage opportunities between contacts. A node's links to neighbours are redundant when the neighbours are already connected with each other and can thus bypass the focal node. Following Latora $e t a l,{ }^{22}$ we defined a node $i$ 's effective size as a function of the node's degree $\mathrm{k}_{\mathrm{i}}$ and its binary local clustering coefficient $c c_{i}$ (defined as the ratio between the number of actual triangles centred on the node $\mathrm{i}$ and the maximum possible number of such triangles; see online supplementary S.5.2 for details). ${ }^{24}$ Thus, the more a node's neighbours are connected with each other, the more closed triangles are centred on the node, and the lower the value of the effective size of the node (see online supplementary S.5.3 for details). 


\section{Efficiency $\left(e_{i}\right)$}

This is the normalised effective size of a node $i$, that is, the ratio between node $i$ 's effective size $e s_{i}$ and its degree $k_{i}$. To facilitate the interpretation of the estimated regression coefficients, all values of efficiency were standardised (see online supplementary S.5.3 for details).

\section{Geographical dispersion of collaborations}

To capture the geographical dispersion of a country's collaborative activities, the geographical entropy $\varepsilon_{i}$ of country $i$ s collaborations was computed (see online supplementary S.5.4 for details) ${ }^{25}$ A country's geographical entropy increases as the country: (1) collaborates with (organisations located in) more countries and (2) devotes an equal amount of collaborative effort towards each of these countries. To facilitate the interpretation of the estimated regression parameters, all values of geographical entropy were standardised.

\section{Control variables}

Two additional country-level characteristics were controlled for: (1) average contribution to publication of international collaborators, $\left\langle p_{a_{i}}^{i n t}\right\rangle$, that is, the degree to which international collaboration contributed on average to an article published by country i and (2) average number of publications per domestic organisation, $\left\langle A_{\text {org }}\right\rangle$, that is the ratio between the total number of articles published by country $i$ and the total number of unique organisations in country $i$ (see online supplementary S.5.5 and figure S4 for details). Moreover, fixed effects for countries' geographical regions were estimated.

\section{Statistical analysis}

A summary of the names, symbols and interpretation of all dependent and independent variables used in the regression analysis is provided in table 1 . To investigate the association between brokerage and geographical entropy on the one hand and research impact and innovation on the other, efficient generalised methods-of-moments (GMM) instrumental-variables two-step estimators were computed that are robust to heteroskedasticity (see online supplementary S.6 for details). For country i, we estimated the following two models:

$$
\operatorname{snc}_{i}=\beta_{1}+\beta_{2}\left\langle p_{a_{i}}^{i n t}\right\rangle+\beta_{3}\left\langle A_{\text {org }_{i}}\right\rangle+\beta_{4} e_{i}+\beta_{5} \varepsilon_{i}+\sum_{k=6}^{11} d_{k, i} \beta_{k}+u_{i}
$$

and

$i i_{i}=\beta_{1}+\beta_{2}\left\langle p_{a_{i}}^{i n t}\right\rangle+\beta_{3}\left\langle A_{\text {org }_{i}}\right\rangle+\beta_{4} e_{i}+\beta_{5} \varepsilon_{i}+\sum_{k=6}^{11} d_{k, i} \beta_{k}+u_{i}$,

where $\left\langle p_{a_{i}}^{\text {int }}\right\rangle,\left\langle A_{\text {org }}\right\rangle, e s_{i}$, and $\varepsilon_{i}$ are the covariates (as defined in the previous sections; see also table 1$), d_{k, i}$ is the dummy variable for the $k$-th geographical region of country $i, \beta_{1}$ to $\beta_{11}$ are fixed parameters, and $u_{i}$ is the country-level error term. All models were estimated using Stata V.15 (StataCorp LP).

\section{Simulation modelling}

To understand the potential impact of Brexit on the UK's research impact and surgical innovation and to evaluate how any adverse outcomes could be mitigated through suitable strategic collaborations beyond the EU, a number of simulations were carried out based on the real-world network. These simulations involved the severance of UK-EU27 collaborations and their subsequent replacement with collaborations with different geographical clusters, with a view to investigating how the UK's performance would change.

Two simulation studies were conducted, one to assess the effect of such substitutions on research impact and the other the effect on innovation (see online supplementary S.7 for details). To ensure all replacements of collaborations were fair and on the conservative side, all UK-EU collaborations were ranked by their corresponding output (ie, research impact or innovation) and, starting from the worst (lowest performing) one, each collaboration was progressively substituted with a UK-non-EU collaboration. Specifically, for each output, three simulations were conducted in which each UK-EU collaboration was substituted with the UK-non-EU collaboration associated with one of the following three outcome measures: (1) the 25th percentile; (2) the median and (3) the maximum value of the distribution of normalised citations or innovation

Table 1 Summary of variable names, symbols and interpretation

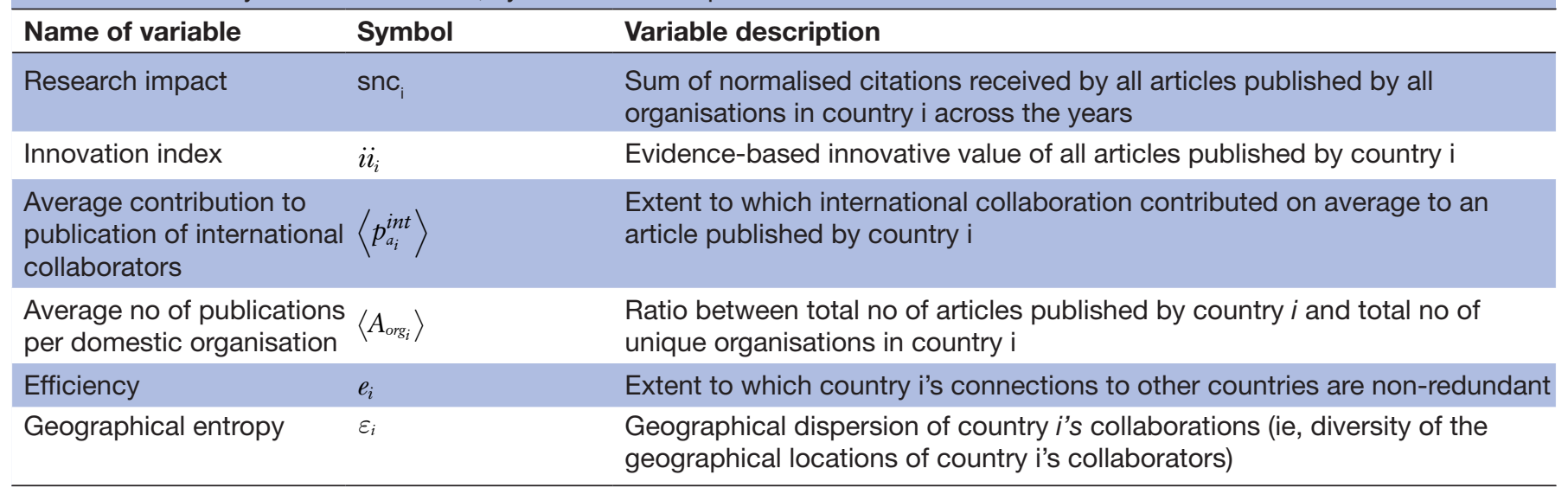




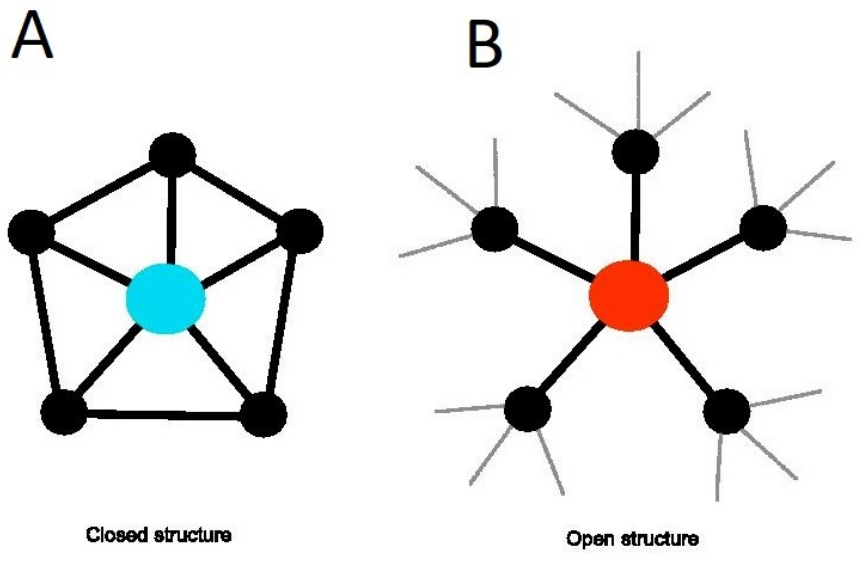

Figure 1 Examples of closed (left) and open (right) egocentred networks of two nodes with the same number of neighbours (ie, collaborators). In (A), the ego-centred network shows a closed structure characterised by multiple closed triangles, while in (B) the ego-centred network shows an open structure (with no closed triangles) where neighbours can reach one another only through the intermediation of the focal (red) node.

index of all articles resulting from all UK-non-EU collaborations. To simulate the effects of newly established UK-non-EU collaborations on performance, three geographical clusters outside the EU were identified: (1) the USA - the international leader in surgical innovation; (2) Asia (including emerging research and innovation powerhouses such as China, South Korea and India) and (3) the 'Rest-of-the-World' (RoW).

\section{RESULTS}

\section{Global collaboration network}

Figure 1 shows two ego-centred networks comprising links between the focal node ('ego') and its neighbours ('alters'), and links between neighbours. The figure shows that two nodes with the same degree (ie, the number of collaborators) can be characterised by different structures of their ego-centred networks. A node collaborating with others that also collaborate with each other has redundant links generating closed triangles and a closed network structure. A node collaborating with disconnected others is characterised by an open network structure, rich in structural holes and brokerage opportunities. $^{22} 24$

Figure 2 (left-hand panel) shows the global collaboration network in robotic surgery consisting of 2397 links connecting 772 organisations across 56 countries, where the thickness of lines is proportional to the intensity of collaboration, and the colour and size of nodes are proportional, respectively, to the research impact and innovation index of the corresponding country. The network in the right-hand top panel only highlights UK-EU collaborations. The right-hand bottom panel shows the association between countries' research impact and innovation on the one hand, and number (ie, degree) and geographical dispersion (ie, entropy) of collaborations on the other.
Global leaders in surgical innovation and their collaboration profiles

Among all articles in robotic surgery, those involving international collaboration achieved the highest performance in terms of both citations and innovation. By contrast, articles involving no collaboration had the lowest performance. Interestingly, articles that originated solely from domestic collaborations had only a marginal superior performance to those involving no collaboration at all, both scoring significantly less than those resulting from international collaborations (in terms of both citations and innovation). The findings are summarised in figure 3 .

The most innovative country in the field of robotic surgery is the USA, followed by Italy and then the UK. Among the top 10 for surgical innovation, there are another four countries from the EU (Netherlands, Spain, Germany and France) and three from Asia (South Korea, China and India). In terms of research impact, the ranking is similar: the USA still ranks first, with the UK also appearing in the top 10 (sixth), along with Canada, Japan and South Korea (ranking second). Figure 4 illustrates the rankings of countries by research impact and innovation. It also depicts the contribution of collaboration patterns (international; domestic; no collaboration) to each country's research impact and innovation. Figure 5 sheds light on the effects of international collaboration on success, by showing the contributions of specific geographical regions and countries to each individual country's research impact and innovation. It becomes apparent that for robotic surgery the UK's primary collaboration partner and largest contributor to both research impact and innovation is the EU followed by the USA.

\section{Regression analysis}

Table 2 shows results from the estimated regression models (see online supplementary tables S3-S6 for descriptive statistics, estimates of all remaining parameters and specification tests). There is no statistically significant difference in performance between two countries that differ in contribution of international collaborations and average number of publications per organisation, after controlling for the other covariates. By contrast, both efficiency and geographical entropy are statistically significantly associated with both measures of performance. After controlling for the other covariates, as efficiency increases by $1 \mathrm{SD}$, a country's normalised citations and innovation value increase by 211.320 and 18.819 units, respectively. Moreover, an increase by 1 SD in geographical entropy is associated with an expected increase of 244.537 units in normalised citations and of 30.850 units in innovation value.

\section{Simulation results}

A number of simulations were carried out to examine the potential effects of replacing EU collaborators with other international partners on the UK's research impact and innovation in robotic surgery. The USA appears the most 


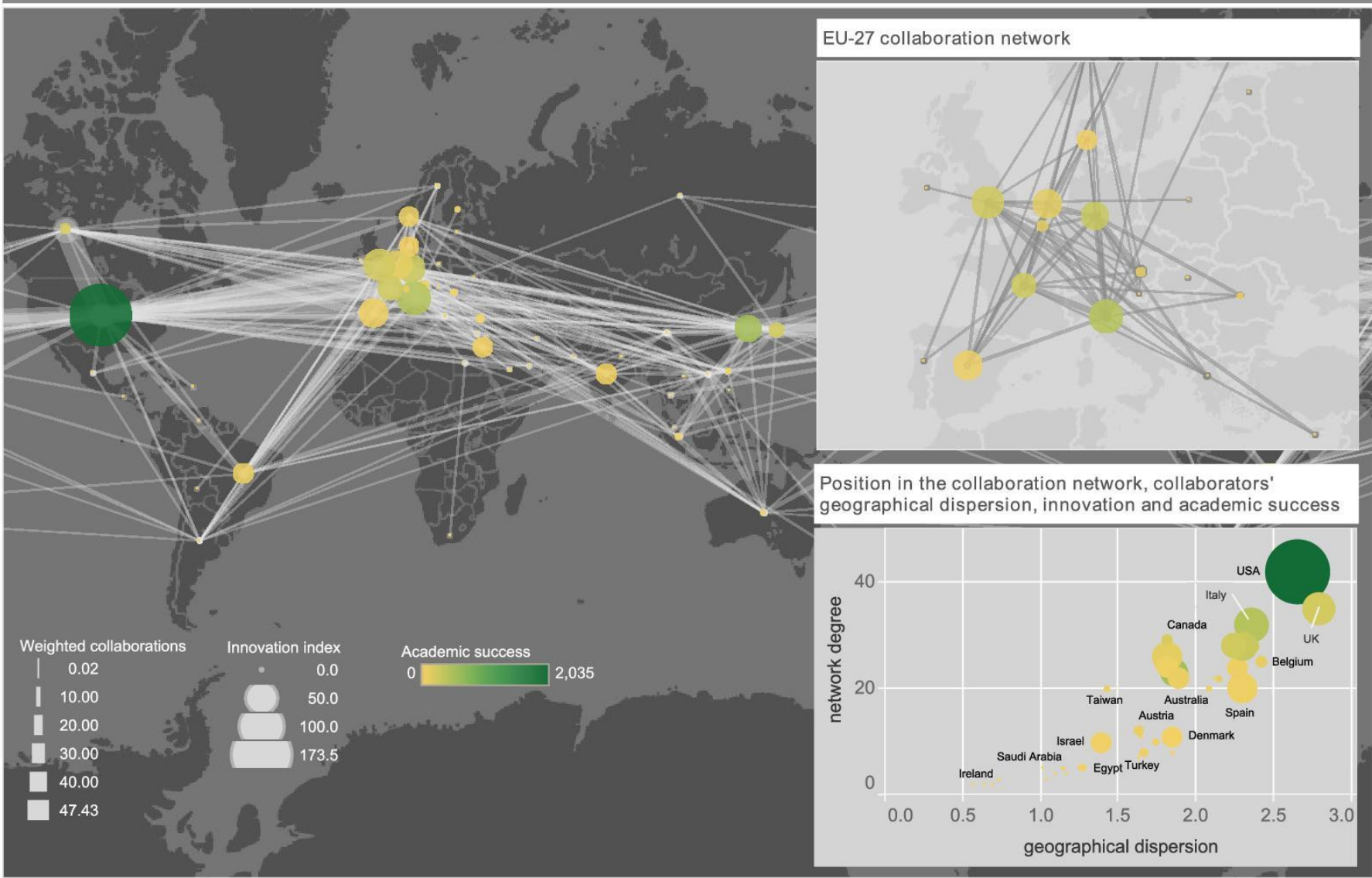

Figure 2 The International collaboration network in robotic surgery. The left-hand panel shows the global collaboration network consisting of 2397 links connecting 772 organisations across 56 countries. The network is weighted, and the thickness of the links corresponds to the intensity of the collaboration between the connected countries. The size of each node is proportional to the corresponding country's innovation index, whereas the colour to the average normalised citations received by the country in the field of robotic surgery. The top right-hand panel shows a zoomed snapshot of the collaboration network between the UK and all EU countries. The bottom right-hand panel shows the association among countries' network degree, geographical dispersion of collaborators, research impact and innovation index. EU: European Union.

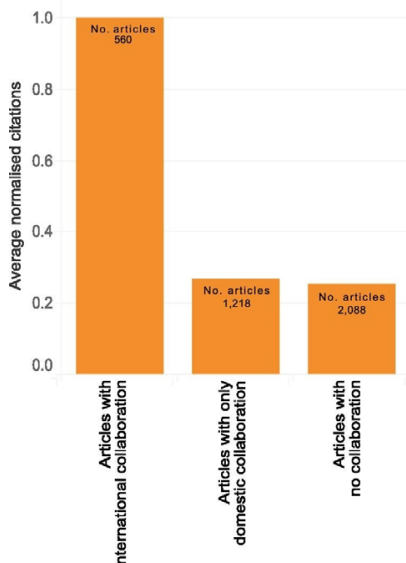

B

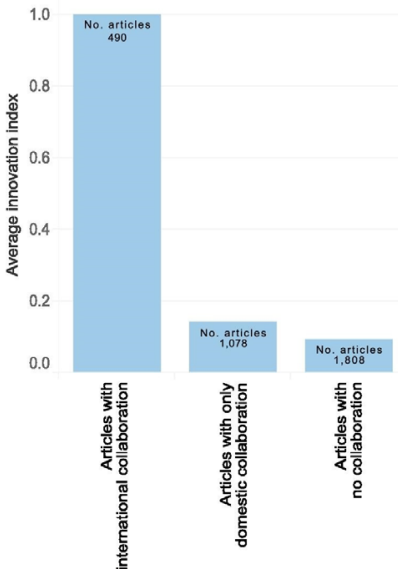

Figure 3 Average normalised citations $(A)$ and innovation index $(B)$ as a function of type of collaboration. Numbers within bars refer to the corresponding number of articles in each category. Average values of both citations and innovation index are divided by the maximum value across the corresponding three sets.

favourable collaboration partner replacing the EU in the event of a 'hard' Brexit (figure 6). If that were the case, the simulation study suggests that the UK's innovation may actually improve, especially if existing collaborations with EU countries were to be replaced with top-performing collaborations with the USA. However, the effect of such substitutions on the UK's research impact would be less pronounced. In particular, the UK's research impact would ultimately suffer if an increasing percentage of UK-EU collaborations were replaced by UK-US collaborations (figure 6A), unless the UK managed to substitute all UK-EU collaborations with high-performing collaborations with the US (figure 6B, C).

Figure 6 also shows that leveraging collaborations with Asian countries would not be as advantageous as with the USA, especially in the event the UK were unable to replace collaborations with EU countries with high-performing ones (figure 6A, D). The simulations also suggest that replacing UK-EU collaborations with collaborations involving RoW countries does not seem to represent an appropriate post-Brexit strategy as this would mostly result 



Type of contribution:

No collaboration

Only domestic collaboration

International collaboration: count ry's cont ribution

International collaboration: foreign contribution

Figure 4 The top 30 countries ranked according to their research impact (top) and innovation index (bottom). Bars are colour-coded to indicate the type of collaboration that contributes to the overall output. The contribution to success of articles involving international collaboration is further split into the contribution attributable to the focal country (orange bar) and the contribution attributable to the foreign collaborators (red bar). Countries are ranked by (total) research impact (A) and innovation (B), starting with the top-ranked on the left.

in a substantial drop in the UK's performance (except in figure 6C, E).

\section{DISCUSSION}

This study evaluated research impact and innovation in robotic surgery, and suggested that a country can benefit from brokering between many and geographically diverse collaborators. The results also illustrate the EU's crucial role in the UK's phenomenal success. Specifically, the EU was shown to represent the UK's largest collaboration partner and, more importantly, its greatest contributor to both research impact and innovation. With Brexit looming, this represents a much-needed study that contributes towards a better understanding of how the UK's collaboration patterns might change and how these changes might affect the UK's research performance.

Despite wide disagreements across the country as to whether Brexit will be beneficial or harmful to the UK, the consensus within the scientific and healthcare communities is that Brexit risks undermining the UK's status as a global leader in science and innovation. ${ }^{10} 26$ The three key mechanisms considered responsible are 
A
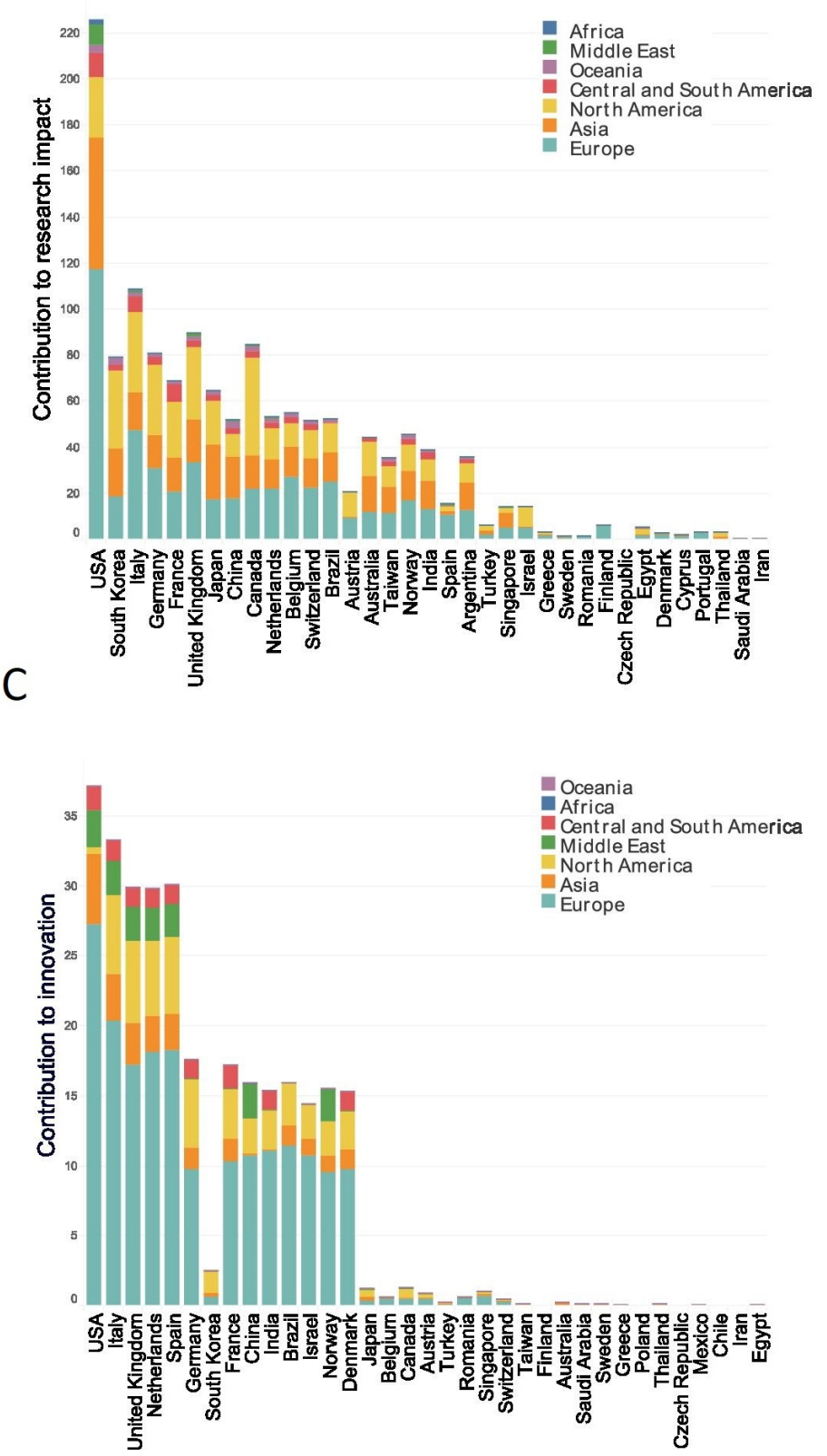

B
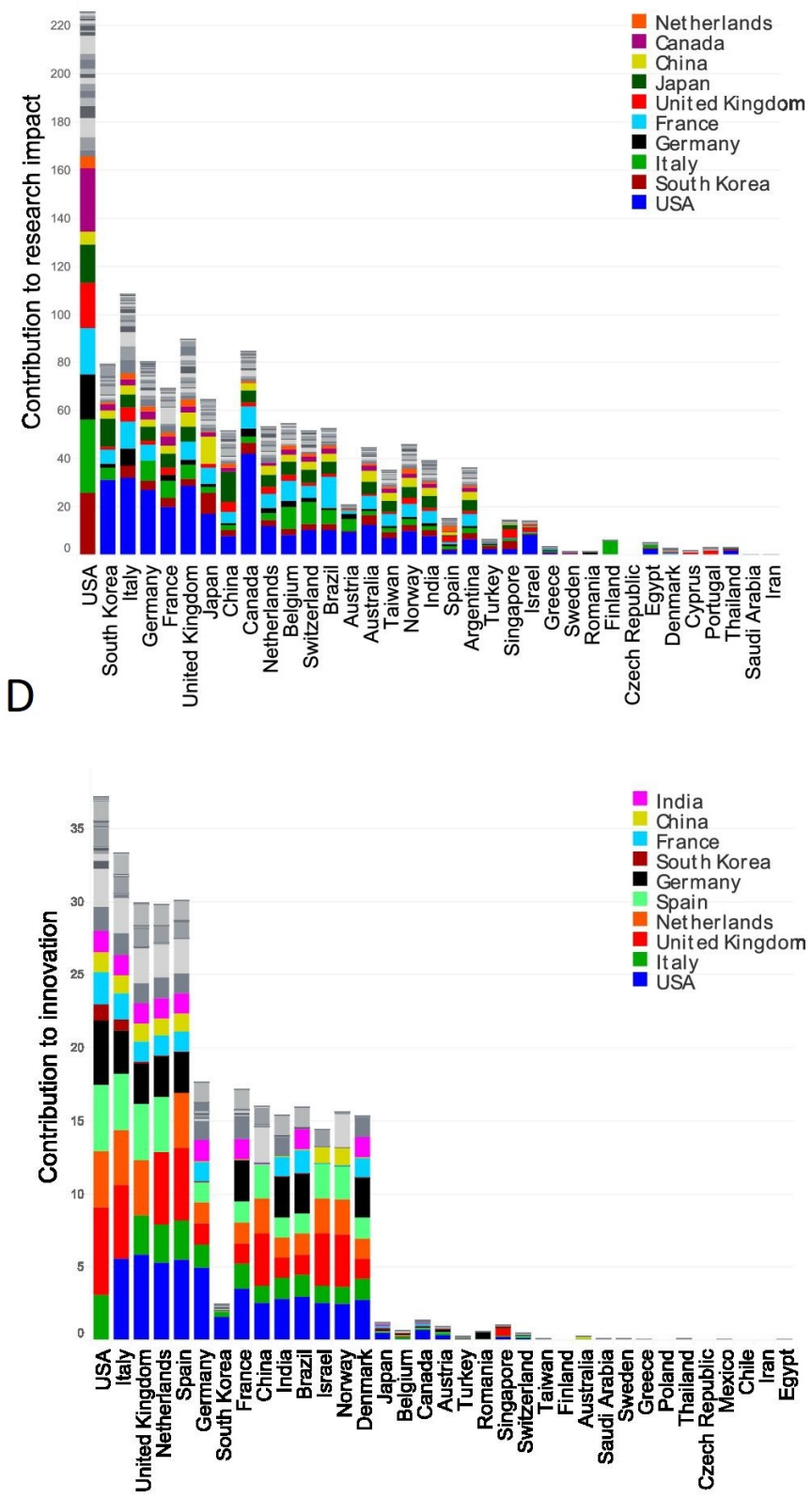

Figure 5 Contribution of geographical regions (A, C) and specific countries (B, D) to countries' research impact $(A, B)$ and innovation index $(C, D)$. Countries are ranked by (total) research impact $(A, B)$ and innovation index $(C, D)$, starting with the top-ranked on the left. The length of each bar corresponds to the contribution to each country's success attributable solely to international collaborators (red bars in figure 4).

funding withdrawal from the EU, loss of EU researchers from UK universities, and disruption of the UK's research and innovation networks - as a result of excluding the UK from European research collaborative agreements and the imposition of restrictions on the free movement of people (including scientists). ${ }^{26}$ Based on our findings, but also on the wider scientific literature, it becomes apparent that for science and innovation the UK has greatly benefited from its collaboration with the EU. This is why 'it is the UK's ambition to build on its uniquely close relationship with the EU, so that collaboration on science and innovation is not only maintained, but strengthened' as explicitly stated by the UK government in its UK-EU future partnership paper. ${ }^{27}$

There are a series of reasons why the UK should be prepared for weakening its current research links with EU countries as a result of Brexit. First, the EU may sever those research links to ensure a competitive advantage in other aspects of the negotiations on the future relationship, such as those relating to protecting its political unity and single market integrity. ${ }^{28}$ It is also expected that the EU would not be keen to give a deserting member and research powerhouse a deal similar to what it currently holds. ${ }^{29}$ But even if the UK managed to remain in the EU's 
Table 2 Instrumental-variables models of countries' research impact and innovation

\begin{tabular}{lcc} 
& Model (1): Research impact & Model (2): Innovation \\
\hline Contribution of international collaborators & $68.272(158.432)$ & $8.109(11.384)$ \\
No of articles per organisation & $33.668(48.883)$ & $-2.363(4.174)$ \\
Efficiency & $211.320(63.625)$ & $\mathbf{1 8 . 8 1 9}(6.108)$ \\
Geographical entropy & $\mathbf{2 4 4 . 5 2 7 ( 5 5 . 7 6 0 )}$ & $\mathbf{3 0 . 8 5 0 ( 4 . 6 4 1 )}$ \\
Constant & $74.600(106.865)$ & $7.116(10.900)$ \\
No observations & 56 & 56 \\
Centred $\mathbf{R}^{2}$ (uncentred $\left.\mathbf{R}^{2}\right)$ & $0.572(0.614)$ & $0.519(0.587)$ \\
Root $\mathbf{M S E}\left(\hat{\sigma}_{e}\right)$ & 184.4 & 17.63 \\
$\mathbf{F}(\mathbf{1 0}, \mathbf{4 5})$ & 3.26 & $\mathbf{7 . 1 7}$ \\
\hline
\end{tabular}

The models are efficient GMM instrumental-variables estimators with SEs robust to heteroskedasticity. Robust SEs of parameter estimates are within parentheses. Reported values of the square root of the MSE refer to the estimated standard deviation $\hat{\sigma}_{e}$ of the idiosyncratic disturbance. Estimated parameters in boldface are statistically significant at the $1 \%$ level $(p<0.01)$.

GMM, generalised methods-of-moments; MSE, mean squared error.

research network, as a non-member, it would undoubtedly lose its existing influence in a number of critical issues such as defining research priorities and directing how EU research funds should be spent. ${ }^{12}$ Furthermore, as a "third country", the UK would likely go 'at the back of the queue' when it comes to accessing EU research facilities. ${ }^{26}$ It is for all these interconnected reasons that it has been argued that 'the most effective way to support UK and European scientific research is for the UK to remain in the EU'. 30

Those supporting Brexit could argue that these are only unfounded speculations. However, factual evidence is increasingly emerging. ${ }^{10} 12262931$ Reports from several leading UK universities have recently documented biases against UK researchers involved in EU programmes including incidents where UK scientists already successful in gaining EU grants were asked not to participate in these programmes following the Brexit vote. ${ }^{29}$ Other recent publications, including from the House of Commons Science and Technology Committee, have suggested that a number of UK researchers were coaxed to withdraw from their leading role in Horizon 2020 programmes, ${ }^{3}$ some research consortia including UK scientists were dismantled following the Brexit vote, ${ }^{3}$ and certain researchers were refused to submit applications for EU grants that included collaborators from the UK. ${ }^{3}$

Despite the well-documented problems caused by the path-dependent nature of institutional relationships, ${ }^{32} 33$ the UK must be prepared for the formation of new strategic partnerships beyond the EU, and not simply await the outcome of the UK-EU future partnership negotiations that will start after Brexit. ${ }^{34-36}$ From this perspective, the simulation studies provide insights into the likely effects of such new strategic partnerships on the UK's scientific performance, and can thus prove valuable in directing the UK's future international strategy. Our study suggests that, within the field of robotic surgery, the best future partner for the UK in the event of a 'hard' Brexit would be the USA, currently its second largest research partner. However, our findings also suggest that the UK could secure an increase in research impact only if collaborations with the EU could always be replaced with top-performing collaborations with the USA, something that would be very difficult and costly to achieve in practice, at least in the short term. On the other hand, the UK's scientific performance may suffer if collaborations with the EU could only be replaced with collaborations with less successful countries or geographical regions (eg, with non-Asian countries) or with less successful organisations in top-performing countries (eg, in Asia).

Thus, the UK's best strategy in the short term might be to try and maintain its academic links to the EU. This represents a more pragmatic approach and is based on the findings that the EU represents the UK's largest collaboration partner and its greatest contributor to both research impact and innovation (see figure 5A-D). In addition to maintaining existing collaborations with the USA, another effective strategy, at least in the short term, would be to reinforce existing (and successful) partnerships with Asian countries. ${ }^{37} 38$ This, combined with the catalytic role of geographical entropy in boosting both citations and innovation, is likely to help the UK to sustain and reinforce its role as an 'open, inclusive and outwardfacing' global country. ${ }^{39}$ Moreover, in the longer term, the establishment of new and strategic relationships with successful research powerhouses such as the USA, China and India will be crucial for maintaining the UK's global leadership in science and innovation in the post-Brexit era. ${ }^{27} 39$

Before concluding, it is important to consider the limitations of this study. The analysis focused on a very specific field, and caution is, therefore, required in generalising the results to other domains. Additional studies would be needed to uncover the role of collaborative networks in different scientific fields. It should also be noted that the dataset used in this study was obtained by searching 
A

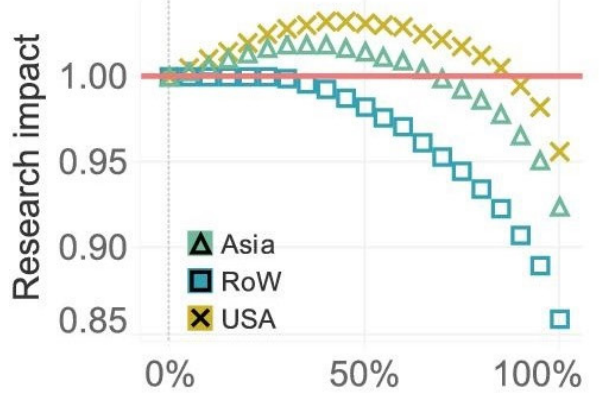

Percentage of substitution
B

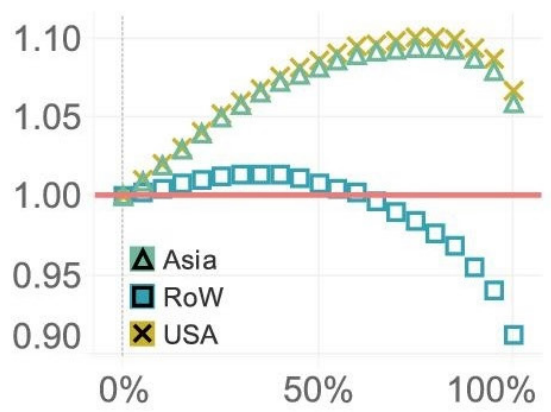

Percentage of substitution

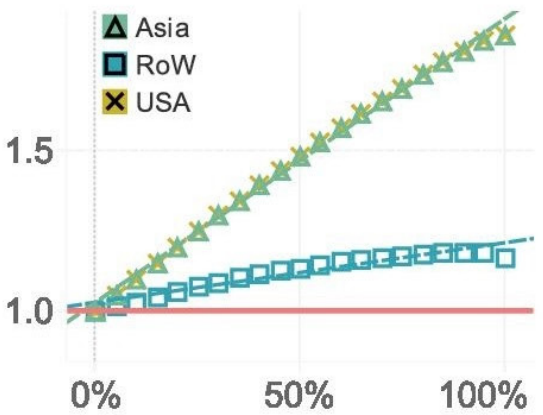

Percentage of substitution

\section{D}
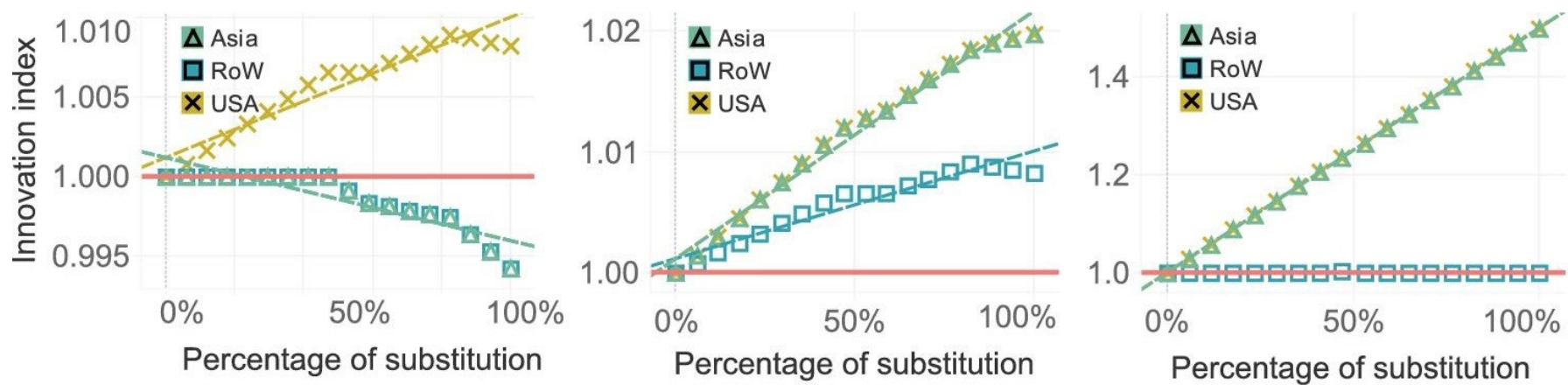

Percentage of substitution

Figure 6 Simulation of the variation in the UK's research impact (top) and innovation index (bottom) as a result of substituting EU collaborators with non-EU collaborators. All articles resulting from a collaboration involving only the UK and one or more of the EU27 countries were ranked from worst to best performing by research impact $(A-C)$ and innovation index (D-F). The performance of various percentages of these articles, starting from the worst performing one, was replaced by the 25th percentile $(A, D)$, the median $(B, E)$, and the maximum value $(C, F)$ of the distributions of research impact $(A-C)$ and innovation index (D-F) of the sets of articles resulting from collaborations involving only the UK and: (1) the USA or (2) Asia or (3) the 'Restof-the-World' (RoW) countries excluding the EU27 members. The red reference line corresponds to the actual value of the UK's performance, normalised to one to facilitate the visual interpretation of the simulation results. Dotted lines refer to best fitted linear trends relating research impact and innovation index to various percentages of substitution of articles. All trend lines have a $p<0.05$, with the only exception of RoW in panel $(F)$ with $p=0.277$. EU: European Union.

only one database-the Web of Science-which in turn integrates a wide range of multidisciplinary research outputs from various sources within a single comprehensive platform. Moreover, the potential loss of EU funding (the UK received from the EU $€ 8.8$ billion for research and innovation in the 2007-2013 period as part of the Horizon 2020 programme grants) ${ }^{40}$ and/or of human capital (almost one in five academics in UK universities are from the EU) ${ }^{41}$ as a result of Brexit have not been accounted for. This makes the simulation models conservative, as those losses would only further deteriorate the UK's performance. Finally, a methodological limitation is chiefly concerned with the use of citation-based metrics as indicators of scientific merit. ${ }^{42}$

Despite these limitations and, more generally, the difficulties faced by models of complex systems in predicting future events and serving as a guide to practice, ${ }^{43}$ our study has a number of strengths. It is the first of its kind in surgical research, using network analysis and simulation modelling, to examine the impact of Brexit on a key area in which, according to the Government's industrial strategy, the UK is set to be a global leader. ${ }^{17}$ This study also comes at a very critical time point, when the level of participation of the UK in future EU programmes on science and innovation is still to be negotiated. By studying the UK's real-world international collaboration network, the findings of this study are likely to be of practical value to the UK government, its negotiators and policy-makers when it comes to setting priorities, making decisions and devising international strategies following Brexit.

As the shape of the future UK-EU relationship is still to be determined, there is no doubt that the decisions to be taken over the coming months and years will be of historical importance and will affect the UK's (and 
EU's) future for many decades to come. Our study on the impact Brexit might have on the UK's scientific research confirms what has long been argued, namely that the UK-EU research partnership has been mutually beneficial and that its continuation represents the best possible outcome for both negotiating parties. Importantly, this study also provides new insights into the value of opportunities for research collaboration beyond the EU that the UK should be seeking to establish. Finally, our network and simulation-based analysis can be seen as a proof of concept for conducting similar studies of other domains that are equally important for the UK's prosperity, such as international trade and financial services, and thus for inspiring policy and directing strategy towards ensuring that the UK remains a global leader in the post-Brexit era.

Contributors GG, IC, PP, AD and TA conceived the study. GG and IC carried out data collection and analysis. GG, IC, VMP, PP, AD and TA contributed to the interpretation of results. GG, IC and PP wrote the manuscript. All authors contributed to critical revisions of various drafts of the manuscript and approve of the final version. $G G$ is the guarantor.

Funding The authors have not declared a specific grant for this research from any funding agency in the public, commercial or not-for-profit sectors.

Disclaimer The views expressed are those of the authors and not necessarily those of The Royal College of Surgeons of England, Imperial College London, and the Alexander S. Onassis Public Benefit Foundation.

Competing interests All authors have completed the Unified Competing Interest (available on request from the corresponding author) and declare: no support from any organisation for the submitted work; no financial relationships with any organisations that might have an interest in the submitted work in the previous three years; Dr. George Garas, MD, FRCS, holds a Royal College of Surgeons of England Doctoral Research Fellowship (grant no. GG 1037600/2017-2018) and is also supported by Imperial College London (grant no. CID 337755/2015-2018) and the Alexander S. Onassis Public Benefit Foundation (grant no. F ZM 014-1/20162017); no other relationships or activities that could appear to have influenced the submitted work.

\section{Patient consent for publication Not required.}

Ethical approval Not required. Open data were used that do not involve patients. Provenance and peer review Not commissioned; externally peer reviewed. Data availability statement Data are available on reasonable request.

Open access This is an open access article distributed in accordance with the Creative Commons Attribution Non Commercial (CC BY-NC 4.0) license, which permits others to distribute, remix, adapt, build upon this work non-commercially, and license their derivative works on different terms, provided the original work is properly cited, appropriate credit is given, any changes made indicated, and the use is non-commercial. See: http://creativecommons.org/licenses/by-nc/4.0/.

\section{REFERENCES}

1. Tijssen R, Yegros A. Uk universities and European industry. Nature 2017;544:35

2. Kazzazi F, Pollard C, Tern P, et al. Evaluating the impact of Brexit on the pharmaceutical industry. J Pharm Policy Pract 2017;10.

3. House of Commons Science and Technology Committee. Leaving the EU: implications and opportunities for science and research. November 2016. London, United Kingdom. Available: https:// publications.parliament.uk/pa/cm201617/cmselect/cmsctech/502/ 502.pdf [Accessed 20 April 2019].

4. HM Government. EU exit long-term economic analysis. November 2018. London, United Kingdom. Available: https://assets.publishing. service.gov.uk/government/uploads/system/uploads/attachment_ data/file/760484/28_November_EU_Exit_-_Long-term_economic_analysis_1_.pdf [Accessed 20 April 2019].

5. HM Government. EU exit long-term economic analysis technical reference paper. November 2018. London, United Kingdom. Available: https://assets.publishing.service.gov.uk/government/ uploads/system/uploads/attachment_data/file/759763/28 November_EU_Exit_Long-Term_Economic_Analysis_Technical Reference_Paper.PDF [Accessed 20 April 2019].

6. HM Government. HM Treasury analysis: the immediate economic impact of leaving the EU. May 2016. London, United Kingdom. Available: https://assets.publishing.service.gov.uk/government/ uploads/system/uploads/attachment_data/file/524967/hm_treasury _ analysis_the_immediate_economic_impact_of_leaving_the_eu_web. pdf [Accessed 20 April 2019].

7. HM Government. HM Treasury analysis: the long-term economic impact of EU membership and the alternatives. April 2016. London, United Kingdom. Available: https://assets.publishing.service.gov.uk/ government/uploads/system/uploads/attachment_data/file/517415/ treasury_analysis_economic_impact_of_eu_membership_web.pdf [Accessed 20 April 2019].

8. Ge J, Polhill JG, Matthews KB, et al. Not one Brexit: how local context and social processes influence policy analysis. PLOS One 2018;13:e0208451.

9. Reijntjes S, Albayaty M, Bush J, et al. The association for human pharmacology in the pharmaceutical industry London meeting 2018: Brexit and other challenges in early phase drug development. Front Pharmacol 2018;9:1301.

10. Halliday A, Hacker J, Brexit HJ. Brexit and European science. Science 2017;358:279.

11. Breckenridge A, Feldschreiber P. Impact of Brexit on UK and EU drug regulation and patient access. Clin Pharmacol Ther 2019;105:923-5.

12. Siva N. UK researchers digest the fallout from Brexit. The Lancet 2016;388:115-6.

13. Shapey IM, Summers AM, Simkin IJ, et al. When politics meets science: what impact might Brexit have on organ donation and transplantation in the United Kingdom? Clin Transplant 2018;32:e13299.

14. Hu Z, Lin G, Sun T, et al. An EU without the UK: mapping the UK's changing roles in the EU scientific research. Scientometrics 2018;115:1185-98.

15. Fahy N, Hervey T, Greer S, et al. How will Brexit affect health and health services in the UK? evaluating three possible scenarios. The Lancet 2017;390:2110-8.

16. Simpkin VL, Mossialos E. Brexit and the NHS: challenges, uncertainties and opportunities. Health Policy 2017;121:477-80.

17. HM Government. Industrial strategy eight great technologies. January 2017. London, United Kingdom. Available: https://www.gov. uk/government/publications/eight-great-technologies-infographics [Accessed 20 April 2019].

18. Garas G, Cingolani I, Panzarasa P, et al. Network analysis of surgical innovation: measuring value and the virality of diffusion in robotic surgery. PLoS One 2017;12:e0183332.

19. Newman MEJ. The structure of scientific collaboration networks. Proc Natl Acad Sci U S A 2001;98:404-9.

20. Ortega JL, Aguillo IF. Institutional and country collaboration in an online service of scientific profiles: Google Scholar citations. $J$ Informetr 2013;7:394-403.

21. Smith $\mathrm{M}$. The trend toward multiple authorship in psychology. Am Psychol 1958;13:596-9.

22. Latora V, Nicosia V, Panzarasa P, et al. Structural holes, and a tale of two measures. J Stat Phys 2013;151:745-64.

23. Garas G, Cingolani I, Panzarasa P, et al. Beyond ideal: the importance of surgical innovation metrics. The Lancet 2019;393:746.

24. Newman MEJ. Networks an introduction. Oxford, United Kingdom: Oxford University Press, 2010.

25. Garas G, Cingolani I, Patel V, et al. Surgical innovation in the era of global surgery: a network analysis. Ann Surg 2018. doi:10.1097/ SLA.0000000000003164. [Epub ahead of print: 20 Dec 2018].

26. Cressey D. Academics across Europe join "Brexit" debate. Nature 2016;530:15

27. HM Government. Collaboration on science and innovation. A future partnership paper. September 2017. London, United Kingdom. Available: https://assets. publishing.service.gov.uk/government/ uploads/system/uploads/attachment_data/file/642542/Science_and_ innovation_paper.pdf [Accessed 20 April 2019].

28. Wilsdon J. UK science, post-Brexit. Science 2017;355:1243.

29. Stokstad E. Europe. uncertainty reigns in Brexit Britain. Science 2016;353:437.

30. . Wellcome seeks Brexit carve-out for UK research. The Lancet 2018;391.

31. Hawkes N. UK scientists would lose money and influence under "Brexit," says Lords report. BMJ 2016;353.

32. Garas G, Ibrahim A, Ashrafian H, et al. Evidence-based surgery: barriers, solutions, and the role of evidence synthesis. World $J$ Surg 2012;36:1723-31.

33. North DC. Institutions. J Econ Perspect 1991;5:97-112. 
34. HM Government. The future relationship between the United Kingdom and the European Union. July 2018. London, United Kingdom. Available: https://assets.publishing.service.gov.uk/ government/uploads/system/uploads/attachment data/file/725288/ The_future_relationship_between_the_United_Kingdom_and_the European_Union.pdf [Accessed 20 April 2019].

35. HM Government. Agreement on the withdrawal of the United Kingdom of great britain and Northern Ireland from the European Union and the European atomic energy community, as endorsed by leaders at a special meeting of the European Council on 25 November 2018. November 2018. London, United Kingdom. Available: https://assets.publishing.service.gov.uk/government/ uploads/system/uploads/attachment_data/file/759019/25 November_Agreement_on_the_withdrawal_of_the_United_Kingdom of Great Britain and Northern Ireland from the European Union and_the_European_Atomic_Energy_Community.pdf [Accessed 20 April 2019].

36. HM Government. Political Declaration setting out the framework for the future relationship between the European Union and the United Kingdom. Novemeber 2018. London, United Kingdom. Available: https://assets.publishing.service.gov.uk/government/uploads/ system/uploads/attachment_data/file/758556/22_November_ Draft_Political_Declaration_setting_out_the_framework_for_the future_relationship_between_the_EU_and_the_UK_agreed_at negotiators_level_and_agreed_in_principle_at_political_level subject_to_endorsement_by_Leaders.pdf [Accessed 20 April 2019].
37. Zhou P, Leydesdorff L. The emergence of China as a leading nation in science. Res Policy 2006;35:83-104.

38. The Royal Society. Knowledge, networks and nations: global scientific collaboration in the 21st century. March 2011. London, United Kingdom. Available: https://royalsociety.org/ /media/ Royal_Society_Content/policy/publications/2011/4294976134.pdf [Accessed 20 April 2019].

39. House of Commons Foreign Affairs Committee. Global Britain. March 2018. London, United Kingdom. Available: https://publications. parliament.uk/pa/cm201719/cmselect/cmfaff/780/780.pdf [Accessed 20 April 2019].

40. The Lancet Infectious Diseases. Looking beyond Brexit: Union without Union. Lancet Infect Dis 2016;16:1203.

41. The Royal Society. UK research and the European Union. The role of the EU in international research collaboration and researcher mobility. May 2016. London, United Kingdom. Available: https:// royalsociety.org/ /media/policy/projects/eu-uk-funding/phase-2/EUrole-in-international-research-collaboration-and-researcher-mobility. pdf [Accessed 20 April 2019].

42. Radicchi F, Fortunato S, Castellano C. Universality of citation distributions: toward an objective measure of scientific impact. Proc Natl Acad Sci U S A 2008;105:17268-72.

43. Kay J. The MAP is not the Territory: models, scientists, and the state of modern macroeconomics. Crit Rev 2012;24:87-99. 